\title{
Classification of Information on Websites and Perceived Risk in Online Transactions
}

\author{
NOJIMA Miho \\ Faculty of Economics, Seikei University \\ E-mail: mnojima@econ.seikei.ac.jp
}

\begin{abstract}
From the perspective of information management and strategy, we spotlight contents of information on the web to solve the problem of perceived risk in online transaction. IT increased the volume of information we acquire, and the volume of information that exceeds human's processing ability has caused perceived risk in online transaction. We attempt to explore the information selection model to solve the problem of the reduction in perceived risk and conduct consumer survey. The empirical study shows that consumers classify information on the web in four types; detailed information, evaluation information of experts and mass media, evaluation information of consumers, and evaluation information in real world. This classification means that consumers think important by whom goods quality and shops sincerity are evaluated. The concept of risk-reducing information and the information classification model from the standpoint of consumers will become the first step of the search on information selection model in the information flood age.
\end{abstract}

Keywords: online retailer, perceived risk, Click \& Mortar, empirical study, Japan

\section{Introduction}

Recently online retailers for consumers (B2C) become popular in Japan. In an investigation in 2002, it was confirmed that the market scale of $\mathrm{B} 2 \mathrm{C}$ reached 1,587 billion yen. (Ministry of Public Management, 2003). However, most online retailers have the problem of earnings, which fall short of expectations.

It is said that consumer's perceived risk is a factor to disturb the development of online trading. Online retailers have to promote consumer's purchase decision making by sending information using a limited method: website. Information on the website plays an important role to reduce 


\section{Nojima}

consumer's uneasiness and help the purchase decision-making.

When IT revolution is discussed, only the technical innovation in the tremendously increased volume of information we acquire and process is paid attention to. Of course, the internet enabled the consumer to reduce various costs concerning information transmission and processing (Clemon, Reddi, \& Row, 1993; Malone, Yates, \& Benjamin, 1987), and to choose better goods by little time and labor (Bakos, 1997). Nevertheless, the problem online retailers confront cannot be explained from the technical point of view. The problem is that human ability of information processing is limited (“Bounded Rationality": Simon, 1945). The problem of consumer's perceived risk might be cause by the way of information transmission. Online retailers should choose appropriate information in consideration of reducing perceived risk. Nowadays, only the information technology proceeds and the effective way of information transmission under the bounded rationality is not discussed enough.

In this research, online retailers' activity is analyzed and the method of offering appropriate information to the consumer is discussed.

\section{Review of Prior Researches}

Bauer (1960) advocates "perceived risk" as the uneasiness consumers hold when they face a new shopping method, and various marketing researches have discussed perceived risk in the context of mail-order system. Recently the problem of the perceived risk begins to attract attention again by the appearance of a new shopping method: online transactions.

The growth of online shops is disturbed because uncertainty and consumer's perceived risks are high amidst various advantages. Actually, consumers think online transactions are risky and hesitate to use the new shopping method (Bhattacherjee, 2002; Einwiller, Geissler, \& Will, 2000; Einwiller \& Will, 2001). Perceived risk in online transaction originates in time and spatial distances between the seller and the purchaser.

There are a lot of researches concerning perceived risk: a series of researches of E-Trust (Arndt, 1967; Cunningham, 1967; Kollock, 1999; Einwiller \& Will, 2001, etc.), and word of mouth that contribute to reduce perceived risk (Mayer, Davis, \& Schoorman, 1995; Mcknight \& Chervany, 1996, 2002, etc.).

In the prior researches, perceived risk and information have been discussed as follows. First of all, the relation between volume of information and the purchase decision-making is discussed. The volume of information, which the consumers acquire promotes purchase (Cox \& Rich, 1964; Dowlin \& Staelin, 1994; Peterson, Balasubramanian, \& Bronnenberg, 1997). When the volume of information increases, the alternatives for consumer's decision-making increases, and a more effective purchase decision-making becomes possible (Peterson, et al., 1997). The marketing theory measures an amount of consumer's 


\section{Information on Websites and Perceived Risk in Online Transactions}

information search action as risk reduction behavior (Cox \& Rich, 1964; Dowling \& Staelin, 1994). However, the quality of the content of information becomes a problem in online transactions while a huge amount of information can be technically displayed on the website. The content of information elaborately chosen by online retailers' efforts can decide their competitive advantages, because the amount of information is provided by technological innovation which all retailers may equally enjoy. Here, research on the content of information originate.

Some researches discussed influence which specific information gave to the perceived risk reduction and purchase promotion. For instance, it is clarified that consumer's reputation has large influence on perceived risk reduction and purchase promotion in various experimental studies. Perceived risk of the customer who visited retailers' websites for the first time can be reduced by disclosure of reputations of other customers who had already used the web shop (Arndt, 1968; Cunningham, 1967a, 1967b; Kollock, 1999).

Investigation for an inclusive framework of risk-reducing information is at the stage of groping, although individual risk-reducing information such as reputation have been studied. A pioneering investigation by Roselius (1971) present 11 risk reduction methods (information) and focused the problem of selecting risk-reducing information from several alternatives. He classified effective information corresponding to the kind of perceived risk and consumers' level of perceived risk. Nonetheless, there are a lot of uncertain points to the content of information, and the number of researches which focused the framework of information selection is limited (Danyi \& Shao, 2003; Nojima 2000; Nojima, Shintaku, Takeda, \& Kokuryo, 2002). It remains a question what kind of information online retailers should publish in their websites.

Information selection becomes an important subject under the online environment, but in the prior researches it had not been much discussed. The necessity of the information selection can be explained from the concept of "Bounded Rationality" (Simon, 1945). We often think that perceived risk will be reduced if retailers offer plenty of information. The truth is that consumers are drowning in the flood of information. IT innovation has changed technological ability of information transmission and accumulation, but does not change human ability of information processing. It is very difficult for us to pick up useful information in the middle of huge amount of information (Kokuryo, 1999). The effort to select and send appropriate information to customers is needed to acquire customers.

\section{Experimental Investigation of Risk-reducing Information}

Prior to thinking about information selection framework, we investigated typical information on online retailers' websites in Japan. Table 1 shows a summary of information, which typical online 
Table 1.

\begin{tabular}{l|l|c|c}
\hline & Risk-reducing information & Average & Variance \\
\hline 1 & Goods and service are famous & 3.28 & 1.32 \\
\hline 2 & Goods can be confirmed in actual store & 3.10 & 1.45 \\
\hline 3 & Online retailer has an actual store & $\mathbf{2 . 8 6}$ & 1.54 \\
\hline 4 & Goods introduced by another website or magazine & $\mathbf{2 . 7 1}$ & 1.22 \\
\hline 5 & Publicity in mass media & $\mathbf{2 . 5 9}$ & 1.19 \\
\hline 6 & Experts evaluate goods & $\mathbf{2 . 4 2}$ & 1.20 \\
\hline 7 & Consumers evaluate goods (BBS) & 3.14 & 1.31 \\
\hline 8 & Consumers evaluate transaction process (BBS) & 3.13 & 1.22 \\
\hline 9 & Stock situation & $\mathbf{4 . 1 2}$ & $\mathbf{0 . 7 8}$ \\
\hline 10 & Delivery method and date & $\mathbf{4 . 2 3}$ & $\mathbf{0 . 6 5}$ \\
\hline 11 & Privacy policy & $\mathbf{4 . 2 4}$ & $\mathbf{0 . 7 4}$ \\
\hline 12 & FAQ & $\mathbf{4 . 3 3}$ & $\mathbf{0 . 6 1}$ \\
\hline 13 & Detailed description of goods & 3.88 & 1.05 \\
\hline 14 & Evaluation and certification by the third party & 3.59 & 1.23 \\
\hline 15 & Webmaster's comment and photograph & 2.96 & 1.35 \\
\hline
\end{tabular}

retailers in Japan offer on the website. We call these information "risk-reducing information," which reduces consumer's perceived risk.

The consumer questionnaire survey was conducted among the internet shopping experienced person in Japan in October 2001, to search consumer's valuation in risk-reducing information. The answers were taken on the web page. As a result, the data of 4750 samples was obtained. The consumer answered the valuing level to risk-reducing information by five scales standard (1: not important, 5: very important). Additionally, the answer concerning the consumer attribute was obtained.
In Table 1, averages and variances of consumer's valuations are shown. Information with high valuing level of four or more on the average was "stock situation," "delivery method and date," "privacy policy" and "FAQ." Variances of valuations are also small, and a lot of consumers think these are important.

Oppositely, "publicity in mass media," "experts evaluate goods," and "goods introduced by another website or magazine," are not relatively valued by consumers. Similarly, it is not much valued whether the online retailer has an actual store.

The effectiveness of click \& mortar has been discussed (Pottruck \& Pearce, 2000). The existing 
enterprise can suppress marketing cost of advertisement and can achieve the synergy effect by using the brand in the real world and distribution infrastructure as well as on internet. Success of click \& mortar company can be explained by stock management, delivery method, and complaint treatment (FAQ), which depend on infrastructure and know-how of existing business. High valuation of these information may have relationship with the success of click \& mortar companies. However, "Online retailer has an actual store" is not valued very much. What does this mean?

\section{Classification Frame of} Risk-reducing Information

In the investigation of descriptive statistics, the know-how of distribution and complaint treatment is highly valued by consumers, and neither the evaluation of the mass media nor the existence of a real store are valued. However, it is impatient to decide the conclusions. We think classification of risk-reducing information is needed.

We enumerate theoretical framework of information classification which can be applied to online transactions. First, perceived risk is classified as "Outcome Risk" and "Consequences Risk" (Roselius, 1971). Corresponding to this classification, risk-reducing information can be divided into prior information and after the fact information. Prior risk-reducing information is information that reduces "outcome risk," risk of the failure of shopping occurances. Detailed information about goods and brand are prior information (Taylor, 1974). After the fact information reduces "consequences risk" concerning the damage caused as a result of the failure of shopping. Product warranty and the repayment system are after the fact information.

This research focus on prior risk-reducing information, for prior information to prevent shopping failing is important to reduce perceived risk. Cox and Rich (1964) describes that the goal of shopping is important, because refund system can not compensate for loss of time and frustrations.

Secondarily, in view of the cause of risks, risk-reducing information can be divided into "information on the goods quality risk," "information on the transaction process risk," and “information on security” (Nojima, 2000; Nojima et al., 2002). Goods quality risk occurs in online transaction because customers cannot actually confirm the goods. The transaction process risk means failure of delivery and the price settlement, and so on. The transaction process risk becomes high in online transaction because of time and spatial distance between sellers and customers. Security prevents danger to consumer's personal information and information leak on the computer network. To analyze risk-reducing information from a business administration aspect, technical solutions like security information will be abstracted.

\section{Classification of Risk-reducing Information Seen from Consumer}

We tried empirical investigation of consumer's 
Nojima

Table 2. Classification of Risk-reducing Information

\begin{tabular}{l|r|r|r|r}
\hline \multicolumn{1}{c|}{ Characteristic value } & 5.124 & 2.251 & 1.187 & 0.986 \\
\hline \multicolumn{1}{c|}{ Risk-reducing information } & $\begin{array}{l}\text { Evaluation } \\
\text { information } \\
\text { of experts } \\
\text { and mass } \\
\text { information }\end{array}$ & $\begin{array}{l}\text { Evaluation } \\
\text { information } \\
\text { of consumers }\end{array}$ & $\begin{array}{l}\text { Evaluation } \\
\text { information in } \\
\text { real world }\end{array}$ \\
\hline Goods and service are famous & 0.107 & 0.250 & 0.111 & $\mathbf{0 . 7 0 9}$ \\
\hline Online retailer has an actual store & -0.017 & 0.396 & -0.007 & $\mathbf{0 . 4 8 8}$ \\
\hline Goods can be confirmed in actual store & 0.113 & 0.179 & 0.140 & $\mathbf{0 . 8 4 8}$ \\
\hline Goods introduced by another website or & 0.064 & $\mathbf{0 . 8 1 0}$ & 0.241 & 0.207 \\
\hline magazine & 0.051 & $\mathbf{0 . 8 2 3}$ & 0.130 & 0.238 \\
\hline Publicity in mass media & 0.030 & $\mathbf{0 . 6 7 8}$ & 0.461 & 0.130 \\
\hline Experts evaluate goods & 0.102 & 0.252 & $\mathbf{0 . 8 6 0}$ & 0.138 \\
\hline Consumers evaluate goods (BBS) & 0.129 & 0.247 & $\mathbf{0 . 8 1 5}$ & 0.089 \\
\hline Consumers evaluate transaction process (BBS) & $\mathbf{0 . 7 8 4}$ & 0.222 & -0.001 & -0.027 \\
\hline Stock situation & $\mathbf{0 . 8 2 0}$ & 0.094 & -0.006 & -0.004 \\
\hline Delivery method and delivery date & $\mathbf{0 . 7 3 5}$ & -0.121 & 0.152 & 0.168 \\
\hline Privacy policy & $\mathbf{0 . 7 6 1}$ & -0.105 & 0.211 & 0.193 \\
\hline FAQ & 0.154 & 0.017 & 0.150 & 0.188 \\
\hline Detailed description of goods & 0.060 & 0.186 & 0.313 & 0.007 \\
\hline Webmaster's comment and photo & 0.329 & 0.189 & 0.094 & 0.119 \\
\hline Evaluation and certification by the third party & & & & \\
\hline
\end{tabular}

Source: Nojima et al. (2002).

behavior to classify risk-reducing information.

Principal component analysis was done with the above-mentioned data of consumers' valuation of risk-reducing information.

When the principal ingredient was analyzed after standardization of data, the characteristic value to each element became 5.124, 2.251, 1.187, 0.986, 0.870 , and 0.735 . Table 2 shows the element matrix after the varimax rotation of the first-fourth element. We named each element; detailed information, evaluation information of experts and mass media, evaluation information of consumers, and evaluation information in real world.

The first principal component shows that consumer use detailed information or evaluation information before purchase. In addition, evaluation information is subdivided to three by the subject who gives the evaluation. The second principal component shows evaluation on the mass media, and the third principal ingredient shows information on the evaluation which other consumers gave, and the fourth principal ingredient shows evaluation in the 
real world.

In the analysis of descriptive statistics, there was a tendency that consumers value four information, stock situation/delivery method and delivery date/privacy policy/FAQ, which fall in detailed information. These are information on the processes of the delivery and the payment. This analysis shows that valuation of transaction process differ from the evaluation of the goods and the shop in consumer decision making, thus we need another kind of information. Detailed information online retailers announce are important for consumers when they are going to purchase, though the quality of goods and uneasiness concerning sincerity in the shop can be solved by evaluation information by others. Not only their brand in the real world but the fact they offer detailed information may result in click \& mortar companies’ advantage.

\section{Discussion}

We try to operationalize contents on online retailers websites by enumerating 15 information that reduce consumer's perceived risks. And we named these information "risk-reducing information".

The result from which stock management, delivery method, and complaint treatment are valued by consumers is not only the problem of the resource of the online shop and the real store, which has been referred in the prior theory, but also the problem of consumer's information classification. We found that consumers classify information on websites in four types: detailed information, evaluation information of experts and mass media, evaluation information of consumers, and evaluation information in real world. Detailed information such as stock management, delivery method and complaint treatment are distinguished clearly from evaluation information and put on emphasis by consumers.

This classification can be explained by the aspect of who evaluate goods quality and shop sincerity. Detailed information means consumers evaluate goods and shops by themselves, evaluation information of experts and mass media means evaluation by third parties of authority, evaluation information of consumers means evaluation by other consumers, and evaluation information in real world means brand in real world. This classification from the standpoint of consumers will make the analysis on information on the web operationable and will show the effective way of offering information to reduce perceived risk in the information flood age.

We conclude that it is important for online retailers to select information which agrees with consumer's information processing process so as to suppress the load of consumer's information processing ability. Further studies are needed to examine which information is selected in consideration of consumer's attribute.

\section{References}

Arndt, J. (1968a). Perceived risk, sociometric integration, and word of mouth in adoption of a new food product. In D. F. Cox (Ed.), Risk taking and information handling in consumer behavior 


\section{Nojima}

(pp. 289-316). Boston: Graduate School of Business Administration, Harvard University.

Arndt, J. (1968b) Word of mouth advertising and informal communication. In D. F. Cox (Ed.), Risk taking and information handling in consumer behavior (pp. 188-239). Boston: Graduate School of Business Administration, Harvard University.

Bakos, J. Y. (1997). Reducing buyer search costs: Implication for electronic marketplaces. Management Science, 43(December), 1676-1692.

Bauer, R. A. (1960, June). Consumer behavior as risk taking. In R. S. Hancock (Ed.), Dynamic marketing for a changing world: Proceedings of the 43rd National Conference of the American Marketing Association (pp. 389-398). Chicago, IL.

Bhattacherjee, A. (2002). Individual trust in online firms: Scale development and initial trust. Journal of Management Information Systems, 19(1), 213-243.

Clemons, E. K., Reddi, S. P., \& Row, M. C. (1993). The impact of information technology on the organization of economic activity: The "move to the middle" hypothesis. Journal of Management Information Systems, 10(2), 9-35.

Cox, D. F., \& Rich, U. S. (1964). Perceived risk and consumer decision-making: The case of telephone shopping. Journal of Marketing Research, 1(November), 32-39.

Cunningham, M. S. (1967a). The major dimensions of perceived risk. In D. F. Cox (Ed.), Risk taking and information handling in consumer behavior (pp. 82-108). Boston: Graduate School of Business Administration, Harvard University.

Cunningham, M. S. (1967b). Perceived risk as a factor in informal consumer communications. In D. F. Cox (Ed.), Risk taking and information handling in consumer behavior (pp. 265-288). Boston: Graduate School of Business Administration, Harvard University.

Danyi, S., \& Shao, L. (2003, July). What makes consumers trust B2C? Proceedings of 7th Pacific Asia Conference on Information Systems (pp. 10-13). Adelaide.

Dowling, G. R., \& Staelin, R. (1994). A model of perceived risk and intended risk-handling activity. Journal of Consumer Research, 21(June), 119-134.

Einwiller, S., Geissler, U., \& Will, M. (2000). Engendering trust in internet business using elements of corporate branding. In H. M. Chung (Ed.), Proceedings of the 2000 Americas Conference on Information Systems (pp. 733-739). Long Beach, CA.

Einwiller, S., \& Will, M. (2001). The role of reputation to engender trust in electronic markets. Proceedings of the Fifth International Conference on Corporate Reputation, Identity, and Competitiveness. Paris. Retrieved August 1, 2003, from http://www.communicationsmgt.org/modules/pub/view. php/communicationsmgp-11

Kollock, P. (1999). The production of trust in online market. In E. J. Lawler, M. Macy, S. Thyne, \& H. A. Walker (Eds.), Advances in group processes: Vol. 16. Greenwich, CT: JAI Press. 
Kokuryo, J. (1999). Open architecture strategy. Tokyo: Daiyamondo-sha. (In Japanese)

Malone, T. W., Yates, J., \& Benjamin, R. I. (1987). Electronic markets and electronic hierarchies. Communications of the ACM, 30(6), 484-497.

Mayer, R. C., Davis, J. H., \& Schoorman, F. D. (1995). An integrative model of organizational trust. Academy of Management Review, 20(3), $709-734$

Mcknight, D. H., \& Chervany, N. L. (1996). The meanings of trust. (MISRC Working Paper, No. 96-04). Retrieved August 1, 2003, from http://misrc.umn.edu/wpaper/WorkingPapers/9604 .pdf

McKnight, D. H., \& Chervany, N. L. (2002). What trust means in e-commerce customer relationships: An interdisciplinary conceptual typology. International Journal of Electronic Commerce, 6(2), 35-59.

Mcknight, D. H., Cummings, L. L., \& Chervany, N. L. (1998). Initial trust formation in new organizational relationships. Academy of Management Review, 23(3), 473-490.

Ministry of Public Management, Home Affairs, Posts and Telecommunications, Japan (2003). Information \& communication in Japan: White paper 2003.

Nojima, M. (2000). The classification of the business models of internet auctions for consumer: Statistical analysis of internet auctions in the USA. Journal of the Japan Society for Management Information, 9(2), 49-63. (In Japanese)

Nojima, M., Shintaku, J., Takeda, Y., \& Kokuryo, J. (2002). Risk reduction systems of the internet shop. Computer Today, (No. 109), 51-56. (In Japanese)

Peterson, R. A., Balasubramanian, S., \& Bronnenberg, B. J. (1997). Exploring the implications of the internet for consumer marketing. Journal of the Academy of Marketing Science, 25(Fall), 329-346.

Pottruck, D., \& Pearce, T. (2000). Clicks and mortar: Passion driven growth in an internet driven. San Francisco: Jossey-Bass.

Roselius, T. (1971). Consumer rankings of risk reduction methods. Journal of Marketing, 35(January) 56-61.

Simon, H. A. (1945). Administrative behavior. New York: Free Press, Division of Macmillan.

Taylor, J. W. (1974). The role of risk in consumer behavior. Journal of Marketing, 38(April), 389-398

[Received July 16, 2004; accepted July 24, 2004] 


\section{Nojima}

